\title{
Phonological Evidences Which Separate and Unite Mamboro Language from Proto Wanokaka-Anakalang in Sumba Group of Languages
}

\author{
Budasi, I. G. \\ Faculty of Language and Art Undiksha, A’ Yani 67, Singaraja-Bali, INDONESIA
}

\begin{abstract}
This article describes the separating and uniting phonological evidences of Proto Wanokaka-Anakalang (PWn-An) and Mamboro language $(\mathrm{Mb})$ reflected from the phonological changes of the Proto Mamboro-Wanokaka-Anakalang (PMb-WnAn) phonemes. The description is based on the types of phonological changes suggested by Jeffers and Lehiste (1979). This article shows that the three phonemes of PMb-Wn-An were found 'retention' in PWn-An, but underwent 'split' in Mb and one phoneme underwent 'monophthongization'. One phoneme of PMb-Wn-An underwent 'substitution', in PWn-An, but 'retention' in $\mathrm{Mb}$. One phoneme of PMb-Wn-An was found 'split' in PWn-An, but 'retention' in Mb. Whereas, the uniting evidences show that three PMb-Wn-An phonemes were found 'retention' both in PWn-An and Mb. One phoneme of PMbWn-An underwent 'split' both in PWn-An as well as in Mb.
\end{abstract}

Key words: Retention, split, monophthongization, substitution, retention, types of phonological changes.

\section{INTRODUCTION}

Proto Sumba is the protolanguage ${ }^{*}$ of all seven languages of Sumba which form a group of languages under Central Malayoo Polynesia (Budasi, 2007). The seven languages which includes: Kodi (Kd), Wewewa, Laboya (Lb), Kambera (Km), Mamboro (Mb), Wanokaka (Wn), and Anakalang (An) languages are actively spoken at present by Sumbanese living in Sumba island East Nusa Tenggara (ENT). The protolanguage was reconstructed in Budasi's study (2007) based on a comparative method. The quantitative data of the study was analyzed using lexicoststistic analysis and the qualitative in the forms of fonem corespondeces and shared innovation were found to support the quantitive findings of the study. Quated from Budasi's study, the relatedness among the seven languages in Sumba and two languages outside Sumba as comparation is quantitatively presented as follows:

The Quatitative Relatedness among the Seven Languages of Sumba and Two Languages outside Sumba: Bima language $(\mathrm{Bm})$ in West

\footnotetext{
Protolanguage is not the real form of a language, but a language form which is constructed through theoretical hypothesis. It is a theoretical construction built through arranging language system that has historical relation, through the description of some simple principles which are built and reconstructed as the pictures of the history of a language (Bynon, 1979; Jeffers, 1979; Mbete, 1990).
}

Nusa Tenggara and Sawu language (Sw) in East Nusa Tenggara.

\begin{tabular}{lllllllllll}
\hline $\mathrm{Km}$ & - & & & & & & & \\
$\mathrm{Kd}$ & 56 & & & & & & & \\
$\mathrm{Lb}$ & 58,5 & 59,5 & & & & & & \\
$\mathrm{An}$ & 69 & 54 & 65,5 & & & & & & \\
$\mathrm{Mb}$ & 69 & 57 & 67 & 70,5 & & & & & \\
$\mathrm{Ww}$ & 53 & 56 & 65,5 & 62 & 66 & & & & \\
$\mathrm{Wn}$ & 60,5 & 66 & 65,5 & 75,5 & 66,5 & 56,5 & & & \\
$\mathrm{Sw}$ & 34 & 34 & 34,5 & 34.5 & 34 & 35 & 34 & & \\
$\mathrm{Bm}$ & 31,5 & 27 & 32 & 31 & 32,5 & 32,5 & 27 & 26 & - \\
\hline & $\mathrm{Km}$ & $\mathrm{Kd}$ & $\mathrm{Lb}$ & $\mathrm{An}$ & $\mathrm{Mb}$ & $\mathrm{Ww}$ & $\mathrm{Wn}$ & $\mathrm{Sw}$ & $\mathrm{Bm}$ \\
\hline
\end{tabular}

Based on this table, a tree diagram of the seven languages have successfully been determined in Budasi's study (2007). Three diagram is as follows.

\section{Explanation of Diagram 1}

(1) Based on the diagram above, the seven languages in Sumba Island have formed a group of languages of Sumba. They are connected on 58\% of cognate percentage reaching the cognate percentage limit for sub-group language for language family subgroup (lexicostatistic criteria determined by Swadesh (1952).

(2) Sumba group of languages consists of two subgroups language:
a) $\mathrm{Kd}$
b) $\mathrm{Ww}, \mathrm{Lb}, \mathrm{Km}, \mathrm{Mb}$, Wn, and $\mathrm{An}$ 


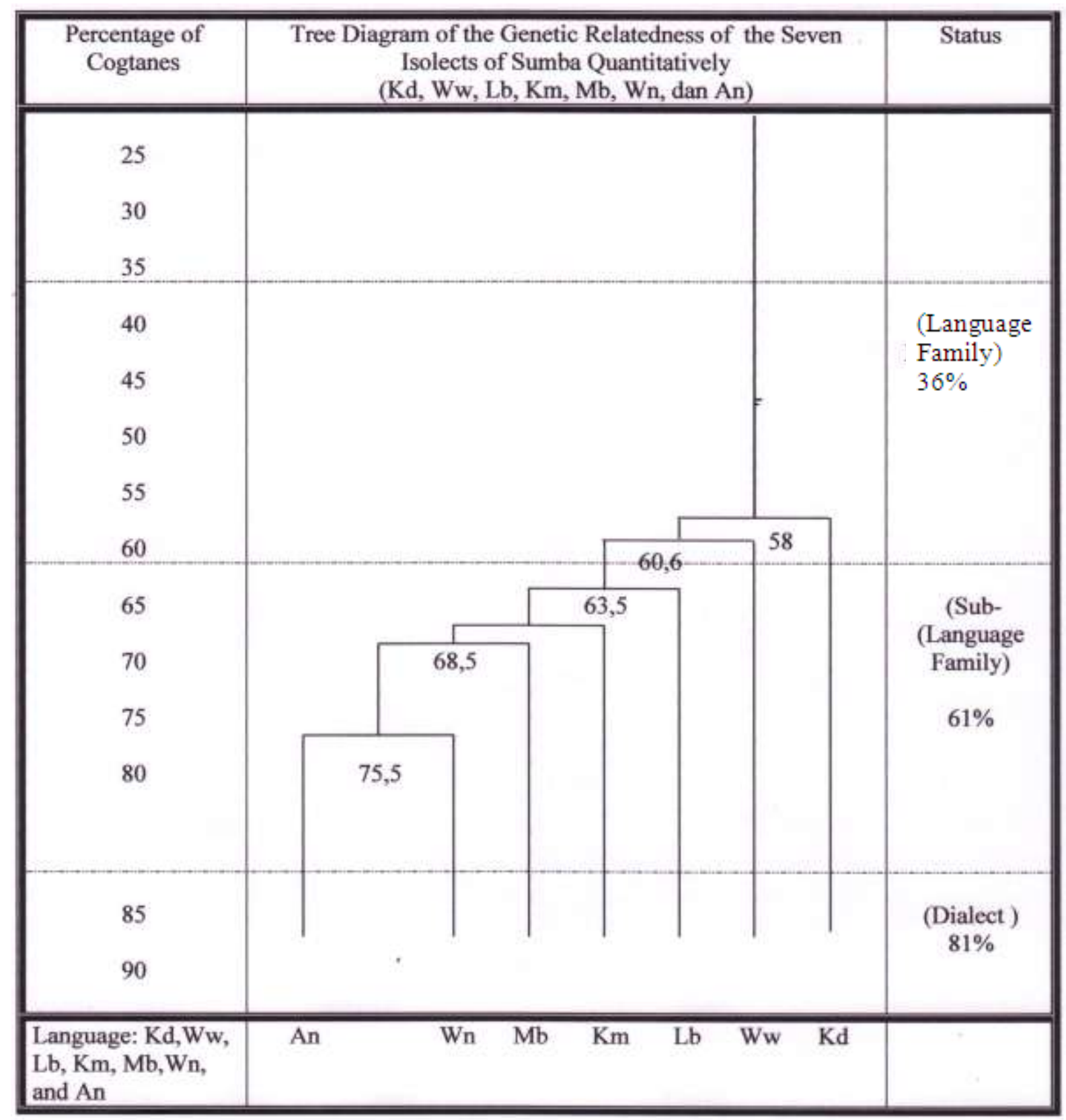

Adapted from Budasi (2007).

Diagran 1. The Tree Diagram of the Genetic Relatedness of the Seven Languages (Kd, Ww, Lb, Km, Mb, Wn, and An) of Sumba Quantitatively. Note: (Bm and Sw are not included in this diagram, The two languages are belonged to Sumba Group of Languages).

(3) Subgroup of (2) b above consists of 2 smaller subgroups:

a) $\mathrm{Ww}$

b) $\mathrm{Lb}, \mathrm{Km}, \mathrm{Mb}, \mathrm{Wn}$, and $\mathrm{An}$

(4) Subgroup (3) b above consists of 2 smaller subgroups:

a) $\mathrm{Lb}$

b) $\mathrm{Km}, \mathrm{Mb}, \mathrm{Wn}$, and $\mathrm{An}$

(5) Subgroup (4) b above consists of 2 smaller groups:
a) $\mathrm{Km}$
b) $\mathrm{Mb}, \mathrm{Wn}$, and $\mathrm{An}$

(6) Subgroups (5) b above consists of 2 smaller subgroups:

a) $\mathrm{Mb}$

b) Wn and An

(7) Subgroup (6) b above has 2 languages, they are Wn and An

Sub-group $\mathrm{Kd}$ and $\mathrm{Ww}, \mathrm{Lb}, \mathrm{Km}, \mathrm{Mb}, \mathrm{Wn}, \mathrm{An}$ are connected on the average percentage 58\%; sub-group $\mathrm{Ww}$ and $\mathrm{Lb}, \mathrm{Km}, \mathrm{Mb}, \mathrm{Wn}, \mathrm{An}$ are connected on $60.60 \%$; subgroup $\mathrm{Lb}$ and $\mathrm{Km}, \mathrm{Mb}, \mathrm{Wn}, \mathrm{An}$ are connected on $63.50 \%$; subgroup $\mathrm{Km}$ and $\mathrm{Mb}, \mathrm{Wn}$, 


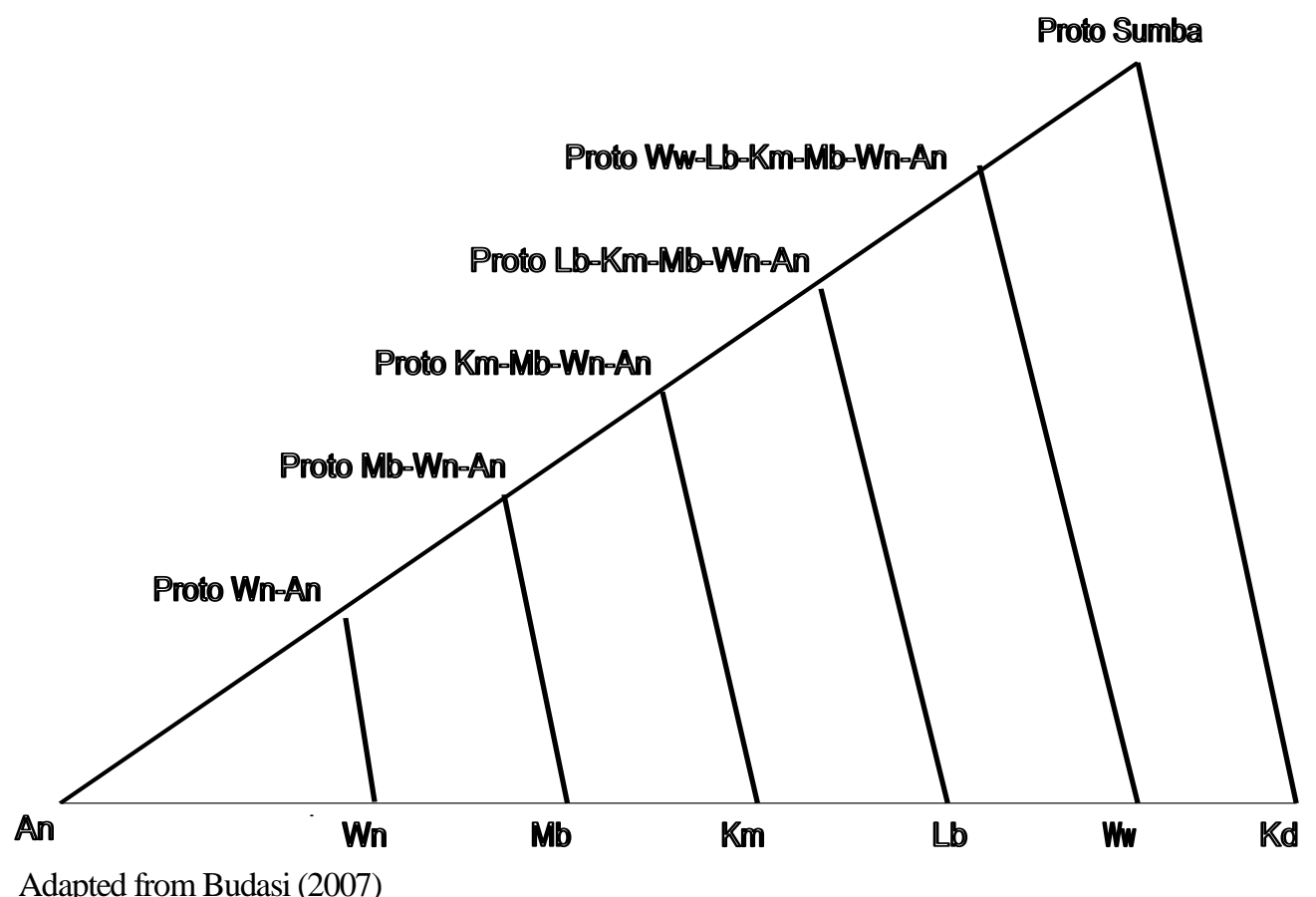

Diagram 2. Family Tree Diagram of Languages in Sumba in ENT Qualitatively

An are connected on 66.17; subgroup $\mathrm{Mb}$ and $\mathrm{Wn}$, An are connected 68.5\%; subgroup Wn and An are connected on $75.5 \%$. Quantitaively, those seven languages are categorized in a language family.

The tree diagram of Sumba group of languages as the result of the qualitative analysis is also presented as follows (Diagram 2).

\section{Explanation of Diagram 2}

1) Proto Sumba (PS) which developed into bipartite: $\mathrm{Kd}$ and $\mathrm{PWw}-\mathrm{Lb}-\mathrm{Km}-\mathrm{Mb}-\mathrm{Wn}-\mathrm{An}$.

2) PWw-Lb-Km-Mb-Wn-An which developed into bipartite: WW and PLb-Km-Mb-Wn-An.

3) PLb-Km-Mb-Wn-An which developed into bipartite: $\mathrm{Lb}$ and $\mathrm{PKm}-\mathrm{Mb}-\mathrm{Wn}-\mathrm{An}$.

4) $\mathrm{PKm}-\mathrm{Mb}-\mathrm{Wn}-\mathrm{An}$ which developed into bipartite: $\mathrm{Mb}$ and $\mathrm{PWn}-\mathrm{An}$ and $\mathrm{Mb}$.

5) PWn-An which developed into bepartite: Wn and An.

Based on diagram 1 and 2, the diagram 1 and digrams 2 mentioned above show that the quanlitative findings confirm the quantitative findings.

$\mathrm{PMb}-\mathrm{Wn}$-An, which becomes the focus of discussion of this article, is one of the protolanguage under Proto Sumba. PMb-Wn-An is a messo language which decended $\mathrm{Mb}$ and PWn-An. The diferences between the two is that $\mathrm{Mb}$ is a real language which is actively spoken by its speakers in Sumba at the present time, whereas PWn-An which decended Wn and An is not the real form of a language. The PWn-An is a language in the abstract form which was reconstructed through theoretical hypothesis based on the quantitative and qualitative approches under the field of historical komparative linguistics (HCL) study. $\mathrm{Mb}$ and PWn-An are the two languages which were decended from PMb-Wn-AN. Lexicostatistically, $\mathrm{Mb}$ and PWn-An are quantitaively related within $68.5 \%$. Based on language classification suggested by Swadesh (1952), Mb and PWn-An can be claasified as two different languages (Budasi, 2007). In relation to this, Fernandez (1988) mentions that if two different languages are classified based on lexicostatistic analysis, the classification must be supported by enough qualitative linguistic evidences. According to Fenandez (1988), the study on language subgrouping and language classification in HCL tradition can be considered complete if it provides quantitative and qualitative linguistic evidences. The question that may arise, is that, what qualitative phonological evidences which separate and unite the $\mathrm{Mb}$ and PWn-An as two different languages are?

This article raises the topic which is relevant to the qualitative evidences in an attempt to answer the question and limits its discussion only on the phonological evidences which separate and unite $\mathrm{Mb}$ and PWn-An. This acrticle is a splinter of Budasi's research dissertation (2007) on the relatedness of the seven languages in Sumba island. The theoretical foundation grounding this study can be discussed in the following. 
Experts in historical comparative lingusitics (HCL) mention that the relatedness of languages in a language family can be proven through a comparative study. The study can be based on the generated elements from the protolanguage to the related languages (Adelaar, 1991; Sneddon, 1978; Fernandez, 1988; Hock, 1988). Actually, protolanguage is not the real form of a language, but a language form which is constructed through theoretical hypothesis. The construction is built through arranging language system that has historical relation and through the description of some simple principles which are built and reconstructed as the pictures of the history of a language (Bynon, 1979; Jeffers \& Lehiste, 1979; Mbete, 1990).

The effort of classifying related languages also means an effort of placing the related languages to have clear relatedness or genetic structures to their protolanguage. Protolanguage reconstruction is not only an effort to conduct language grouping but also to clarify their family relatedness and their protolanguage. The relatedness can be seen from phoneme recurrences (the correspondences of phonemes) in the words which have related meaning. A genetic grouping is the hypothesis about the historical development of the related languages since the genetic language subgrouping explains the similarity of the languages being compared. The similarities that can be observed are the linguistic features which have connection with their protolanguage. In this case, the features that can be observed are the characteristics of their similarities and their relationship to their protolanguage (Fernandez, 1988, 2010; Mbete 2000; Mandala, 2010).

The assumption which underlines this hypothesis, is that, if the condition of the relatedness among languages being compared is normal, the languages originally come from a protolanguage, and the relationship between languages can be stated in a family tree diagram which describes the connection of the parent languages within the era of historical development of the previous language in succession (Durasid, 1990). So, as an abstract system of the related languages, protolanguage becomes the reflection of historical development, that is, the related languages have passed the same development (Birnbaum, 1977).

There are two basis hypothesis in reconstructing protolanguage: relationship hypothesis and regularity hypothesis (Jeffers \& Lehiste, 1979; Hock, 1988). The first hypothesis has the characteristics of the similarities. One of the forms of similarities being considered is the similarities in forms and the meaning of the words. The words which have similar or the same forms and meaning are called cognates.
Those words are not borrowing words but as the inheritances from the same source. The regular hypothesis is in the form of regular and systemic phonological changes that happen in languages decended from protolanguage.

In connection to this, Jeffers and Lehiste (1979) mention that the patterns of phoneme changes can be in the forms of merger (two phonemes or more to be one phoneme); split (one phoneme becomes two phonemes or more), monophonemization (a change of phoneme cluster to be a phoneme), dipthongization (the change of a phoneme to be two clustered phonemes), phonemic loss (the loss of phoneme), and Lenition (weakening phoneme), substitution (one phoneme is substituted by other phoneme), and retention (one phoneme is reflected exactly in the same form).

Hock (1988) states that the inheritance linguistic features from the related language can also be investigated through four linguistic levels: lexical, phonological, morphological, and syntactical. The first two levels are more common used in HCL study and mentions some reasons. Hock provides two reasons as follows: firstly, through lexical reconstruction, culture, social history, and geographical facts of certain language users can be identified; secondly, the most successful study in HCL is in the phonological level due to some factors: a) phonological element is the smallest part of a language, so that it is easy to understand, b) it is easier to find the relevant fact compared with other levels, c) phonology has been professionally studied in linguistic fields, thus it has been a comprehensive study, and d) the regular primary sound changes can indicate the diachronic relationship of the related languages being compared.

Lexical and phonological levels are considered as trivial aspects in comparative studies. This fact can be obviously seen in the studies done by Fernandez (1988); Durasid (1990); Mbete (1990); and Mandala (2010). In their studies, the preliminary observation in investigating the linguistic inheritances was conducted in the lexical level to classify the relationship among the related languages under the studies. In these studies, quantitative evidences focused at glance more on a number of basic vocabularies in order to see the percentage of the relatedness of the languages under studies. Following this was the studies in the phonological level to determine the reconstruction of the languages being observed and their analysis was based on the sound changes found in the languages. The results of the analysis were arranged based on the phoneme correspondence rules (see also Dyen, 1978, and Bynon, 1979). 
Viewed from the effort to classify and reconstruct the related languages, the core problem in the studies is to gain the evidences that can be proved quantitatively and qualitatively (Dyen, 1978). The quantitative evidences can be a group of words that have closed relationship in linguistic features. While the qualitative evidences can be the phonological corresponddences and shared innovations (Crowley, 1992). In figuring out the quantitative evidences, the linguistic features which are normally used are comparison of a number of basic vocabularies which contain retention words. The basic vocabularies are identified using Swadesh's list (the Blust's revision). The words in the list are believed to have universal characteristics. In HCL, Anceaux (1965) states that the study which makes use of the retention words belongs to quantitative approach (as cited in Fernandez, 1988).

In this case, the study through quantitative approach makes use of lexicostatistics in which the quantitative evidences is used as the basis to do preliminary classification of a language in its purpose of calculating the percentages of the relatedness of the languages being compared. The assumption which underlines this approach is that the vocabularies in a language can be distinguished into two major groups: a) the vocabularies that can not change easily, for instances: the ones which are related to the parts of the human bodies, pronouns, the vocabularies which state: feeling, number, nature, whether, and household equipments. Those vocabularies are considered to exist since the existence of the language. All those vocabularies are placed in a group which can be called basic vocabularies, b) the vocabularies that can change easily, for instance: borrowing words from other cultures. For example: table, chair, shirt, and lamp. These vocabularies are easily defused (as the effect of migration and the change of culture, especially through lexical borrowing and innovation). The next step is to calculate the separation periods of each language from the others by using glottochronology Dyen (1978); Swadesh (1952); Keraf (1991). While the assumption grounding the separation is the retention of a set of words which are universal in characters and constant forever (Dyen, 1978). There are several opinions about the percentages of vocabulary changes in their relation to the shared retention. Swadesh (1952), Hockett (1963), and Dyen (1975) state that the changes normally reach $19 \%$ in a thousand year or can resist until 81\%; Crowley (1992) argues 80\%, while Keraf (1991) mentions $80,5 \%$.

In brief, it can be concluded that both quantitative and qualitative evidences can be used to classify languages and sub-grouping them into related or non- related languages. The quantitative approach makes use of static linguistic evidences based on the theoretical foundation that there are basic vocabularies, especially Swedesh' list, which are assumed to be difficult to change and they remain to exist (retention) in languages. The qualitaive approach make use of the linguistic qualitative evidences which can be in the form the phonological correspondences and shared innovations (Crowley, 1992).

\section{METHOD}

The present study employs a comparative method. The data of the study consisted of etimons of Proto $\mathrm{Mb}-\mathrm{Wn}-\mathrm{An}, \mathrm{PWn}-\mathrm{A}$, and the lexicons of $\mathrm{Mb}$ identified in Budasi' study (2007). The procedures of data analysis were done as follows: 1) the phoneme correspondences between PMb-Wn-An and PWn-An reflected in the etimons of two protoes were conpared and identified; 2) the phoneme correspondences between $\mathrm{PMb}-\mathrm{Wn}-\mathrm{An}$ and $\mathrm{Mb}$ reflected in the etimons of $\mathrm{PMb}-\mathrm{Wn}-\mathrm{An}$ and the lexicon of $\mathrm{Mb}$ were also compared and identified; 3) the reflects of the $\mathrm{PMb}-\mathrm{Wn}$-An phonemes in PWn-An were compared with the reflects of the PMb-Wn-An phonemes in $\mathrm{Mb}$; and 4) the similarities and the differences of the reflects were identified and described based on the patterns of phonological changes suggested by Jeffers and Lehiste (1979) which include: merger (two phonemes or more to be one phoneme); split (one phoneme becomes two phonemes or more), monophonemization (a change of phoneme cluster to be a phoneme), dipthongization (the change of a phoneme to be two clustered phonemes), phonemic loss (the loss of phoneme), and Lenition (weakening phoneme), substitution (one phoneme is substituted by other phoneme), and retention (one phoneme is reflected exactly in the same form).

\section{FINDINGS AND DISCUSSION}

In the tradition of HCL, a qualitative study can result the description of linguistic evidence, which separates or unites languages within a group of language family. The evidences of separation and unition can be described phonologically and lexically. This article limits its discussion only on the phonological evidence which separates and unites $\mathrm{Mb}$ and PWn-An.

\section{Phonological Evidence Separating Mb Language and PWn-An}

Phonlogical evidences separating the $\mathrm{Mb}$ language from PWn-A can be explained through the following examples. 


\begin{tabular}{|c|c|c|c|}
\hline Glos & PWn-An & $\mathrm{Mb}$ & PMb-Wn-An \\
\hline 'flow' & *la-i & le-i & $*$ la-i \\
\hline 'female' & *ba-i & be-i & *ba-i \\
\hline 'wase' & $*$ ta-i & te-i & $*$ ta-i \\
\hline 'water' & ${ }^{*}$ wa-i & we-i & $*_{w a-i}$ \\
\hline 'this' & *na-i & na-i & *na-i \\
\hline 'pound' & *ba-i & mba-i & $*(\mathrm{~m}) \mathrm{ba}-\mathrm{i}$ \\
\hline 'bring' & *pala-i & pala-i & *pala-i \\
\hline 'tree' & ${ }^{*}$ ya-i & ya-i & ${ }^{*}$ ya-i \\
\hline
\end{tabular}

A number of sample mentioned above show that diphtong PMb-Wn-An *a-i in ultima underwent 'retention' in PWn-An, while in Mb language itself underwent innovation in the form of 'split' > $\mathrm{Mb}$ e-i, an a-i. PMb-Wn-An *a-u in ultima and penultima underwent 'retention' in PWn-An, while in $\mathrm{Mb}$ underwent 'split' > Mb $\underline{u}$ and $\underline{\mathrm{o}-\mathrm{u}}$. Diphtong PMbWn-An *u-a in ultima underwent 'retention' in PWn$\mathrm{An}$, whereas in $\mathrm{Mb}$ underwent innovation $>\mathrm{Mb}$ a. $\mathrm{A}$ number of evidence which separated $\mathrm{Mb}$ and $\mathrm{PWn}$ An can be seen in the following examples.

\begin{tabular}{|c|c|c|c|}
\hline$\overline{\text { Glos }}$ & PWn-An & $\mathrm{Mb}$ & PMb-Wn-An \\
\hline 'tired' & *ja-uli & oja & *ja-uli \\
\hline 'swelling' & *ba-u & $\mathrm{mbu}$ & $*(\mathrm{~m}) \mathrm{ba}-\mathrm{u}$ \\
\hline 'neck hair' & *kaha-uki & kasuki & *kasa-uki \\
\hline 'shining' & *la-uүu & lo-uүu & *la-uпu \\
\hline 'acid' & $*_{\text {mara-u }}$ & maro-u & $*_{\text {mara-u }}$ \\
\hline
\end{tabular}

A number of example mentioned above show that dipthong PMb-Wn-An *a-u in ultima and penultima positions underwent 'retention' in $\mathrm{PWn}-\mathrm{An}$, while in $\mathrm{Mb}$ underwent splite $\mathrm{Mb} \underline{a}, \underline{u}, \underline{\mathrm{o}-\mathrm{u}}$, and $\underline{\mathrm{a}-\mathrm{i}}$. A number of phonological evidences which separate $\mathrm{Mb}$ language and PWnn-An can be seen in the following examples:

\begin{tabular}{llll}
\hline Glos & PWn-An & Mb & PMb-Wn-An \\
\hline 'dig up' & *haka & saka & *saka \\
'foot' & *wihi & wisi & *wisi \\
'neck hair' & *kaha-uki & kasuki & *kasa-uki \\
\hline
\end{tabular}

In the first two examples above, PMb-Wn-An *s in ultima and penultima position underwent innovasion in the form of 'substitution' >PWn-An *h, whereas in $\mathrm{Mb}$ underwent 'retention'. See also the following examples.

\begin{tabular}{|c|c|c|c|}
\hline Glos & PWn-An & $\mathrm{Mb}$ & PMb-Wn-An \\
\hline 'spider' & *gegi & 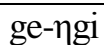 & *gegi \\
\hline 'hair' & *logi & lo-ngi & $* \operatorname{logi}$ \\
\hline
\end{tabular}

Dorsovelar stop voiced fonem PMb-Wn-An *g in ultima underwent 'substitution', cluster nassal consonat $\mathrm{Mb}{ }^{*} \eta \mathrm{g}$, whereas underwent 'retention' in PWn-An. The evidence can be seen in the following examples.

\begin{tabular}{llll}
\hline Glos & PWn-An & Mb & PMb-Wn-An \\
\hline 'come back' & $*(\mathrm{~m})$ bali & mbali & $*(\mathrm{~m})$ bali \\
'broken' & $*(\mathrm{~m})$ bera & mbera & $*(\mathrm{~m})$ bera \\
'swelling' & *ba-u & mbu & $*(\mathrm{~m})$ ba-u \\
'pound' & *ba-i & mba-i & $*(\mathrm{~m})$ ba-i \\
'chilly & *baku & mbaku & $*(\mathrm{~m})$ baku \\
'wash' & *basa & mbasa & $*(\mathrm{~m})$ basa \\
'knee' & *kabaku & ka-mbaku & *ka(m)baku \\
'smoke' & *sibu & ku-mbi-sa & *ku(m)bisa \\
'peanut' & *kaba-i & ka-mbu-a & *ka(m)ba-i \\
\hline
\end{tabular}

$\mathrm{PMb}-\mathrm{Wn}-\mathrm{An} *(\mathrm{~m}) \mathrm{b}$ in penultima and ultima position underwent 'split' > PWn-An *b and *(m)b. However in $\mathrm{Mb}$ it underwent 'retention'.

\section{Phonological Evidences Uniting Mb and PWn-An}

Phonlogical evidences which united $\mathrm{Mb}$ language and PWn-An were found unique. The uniqueness can be seen in the following examples.

\begin{tabular}{llll}
\hline Glos & PWn-An & Mb & PMb-Wn-An \\
\hline 'medicine' & *moru & moru & *moru \\
'plant egg' & *toru & toru & *toru \\
'neck' & *koku & koku & *koku \\
'cat' & *wodu & wodu & *wodu \\
'uncle' & *boku & boku & *boku \\
'river' & *loku & loku & *loku \\
\hline
\end{tabular}

In the example above, PMb-Wn-An *u within ultima underwent 'retention' > $\mathrm{PWn}-\mathrm{An} * \mathrm{u}$ and $\mathrm{Mb}$ u. In the following examples, PMb-Wn-An *i within ultima position also underwent 'retention' both in $\mathrm{Mb}$ and PWn-An.

\begin{tabular}{|c|c|c|c|}
\hline Glos & PWn-An & $\mathrm{Mb}$ & PMb-Wn-An \\
\hline 'rice' & *pari & pari & *pari \\
\hline ‘dry’ & *dani & dapi & *dapi \\
\hline 'kill' & *pamati & pamati & *pamati \\
\hline 'ladder' & *pahari & pahari & *pahari \\
\hline 'white ant' & *ahi & ahi & *ahi \\
\hline 'case' & *rabi & rabi & *rabi \\
\hline 'heart' & *ati & ati & *ati \\
\hline 'peace' & *padami & nami & *padami \\
\hline 'take' & *deki & deki & $*$ deki \\
\hline 'swamp' & $*_{\text {redi }}$ & redi & $*_{\text {redi }}$ \\
\hline 'squit' & *kajeli & kajeli & *kajeli \\
\hline 'rich' & *dedi & dedi & $*$ dedi \\
\hline 'talk' & *panewi & panewi & *panewi \\
\hline 'cuccumber' & *kareri & kareri & * kareri \\
\hline 'friend' & $*_{\text {oli }}$ & oli & *oli \\
\hline 'vegetable' & *rowi & rowi & *rowi \\
\hline 'rottan' & *uwi & uwi & *uwi \\
\hline 'saffron' & *kuñi & kuñi & *kuñi \\
\hline 'nech hair) & *kaha-uki & kasuki & *kasa-uki \\
\hline
\end{tabular}


The following example which means 'year' shows that $\mathrm{PMb}-\mathrm{Wn}-\mathrm{An} * \mathrm{a}$ in penultima underwent 'substitution' > PWn-An *a-u and $\mathrm{Mb} \underline{\mathrm{a}-\mathrm{u}}$.

\begin{tabular}{|c|c|c|c|}
\hline Glos & PWn-An & $\mathrm{Mb}$ & PMb-Wn-An \\
\hline 'year' & $*(\mathrm{n}) \mathrm{da}-\mathrm{u}-\eta \mathrm{u}$ & nda-uๆu & $*(\mathrm{n}) \mathrm{da \eta u}$ \\
\hline
\end{tabular}

In the example below, PMb-Wn-An *s dan *h, both ultima and penultima positions underwent 'split' , PWn-An $*_{\underline{s}}$ and $* \underline{h}$ and $>\mathrm{Mb} \underline{s}$ and $\underline{h}$.

\begin{tabular}{llll}
\hline Glos & PWn-An & Mb & PMb-Wn-An \\
\hline 'island' & *nusa & nuha & *nusa \\
'beach' & *tahika & tahika & *tasika \\
'net' & *kasosa & kasosa & *kasosa \\
'wash' & *basa & mbasa & *(m)basa \\
'dig up' & *haka & saka & *saka \\
'foot' & *wisi & wisi & *wisi \\
'neck hair & *kaha-uki & kasuki & *kasa-uki \\
'ladder' & *pahari & pahari & *pahari \\
'whit ant' & *asi & ahi & *asi \\
\hline
\end{tabular}

The description of the study findings mentioned above show a number of phonological evidences which separate and unite $\mathrm{Mb}$ and PWn-An. The confirmation of the qualitative study findings mentioned above also means that both $\mathrm{Mb}$ and PWn-An can be determined as two different languages under Sumba group of languages. In this case, $\mathrm{Mb}$ is a living language which is actively spoken at the present time, while PWn-An is one of the protolanguages under Proto Sumba which decended Wn and An. This kind of classification is in relation to the HCL theoretical foundation hold in this study, that is, two or more languages can be classified as different languages if there are supporting quantitative and qualitative linguistic evedences that separate and unite the languages being compared in this deciplines. Based on this study findings, $\mathrm{Mb}$ and $\mathrm{PWn}-\mathrm{An}$ can also be stated as different languages which were decended from their language proto, $\mathrm{PMb}-\mathrm{Wn}-\mathrm{AN}$. In addition, they are grouped under Sumba group of languages.

In relation to the classification of languages in Sumba, following Uhlenbeck (1971), Dyen (1982) states that there is only one language in this island which he names Sumba language. So, the investigation of this study is quite different from Dyen's opinion. If it is stated that in Sumba there is only one language, Dyen's statement also means that all isolects of Sumba quatitatively determined in Budasi (2007) as different languages in Sumba-East Nusa Tenggara are considered as dialects of Sumba language. Therefore, this study findings are in contradictive to Dyen' opinion which was based on the opinion of Uhlenbeck's statement and was without in depth-field study. This study, however, supports the study done by Grimes (1988) who states that there are seven languages in Sumba which include: An, Wn, Mb, $\mathrm{Km}, \mathrm{Ww}, \mathrm{Lb}$, and $\mathrm{Kd}$, inspite of the fact that Grimes and Grimes' study was based on the opinion of the speakers of the seven languages.

To complete the language subgrouping of the eight Sumba languages, several other corresponding studies need to be done. Though in this study the phonological evidence that separates and unites $\mathrm{Mb}$ and PWn-An have been identified, other four linguistic levels: the morphological, syntatical, semantic, and sociolinguistic, also need to be indentified to complete the subgrouping languages.

\section{CONCLUSION}

The description in the early section shows a number phonological evidences separating and uniting $\mathrm{Mb}$ and PWn-An. The evidences appear in the different reflects of PMb-Wn-An in $\mathrm{Mb}$ and in PWn-An. The phonological evidences separating $\mathrm{Mb}$ and $\mathrm{PWn}-\mathrm{An}$ was found in the form of vocal fonemes as well as in the form of diphtongs, such as: a) PMb-Wn-An *a-i in ultima position $>\mathrm{PWn}-\mathrm{An} * \mathrm{a}-\mathrm{i}$, whereas underwent 'split' $>\mathrm{Mb} \underline{\mathrm{e}-\mathrm{i}}$, and $\underline{\mathrm{a}-\mathrm{i}}$; PMb-Wn-An *a-u in ultima and penultima positions underwent 'retention' > PWn$\mathrm{An} * \mathrm{a}-\mathrm{u}$, whereas underwent 'split' > $\mathrm{Mb} \underline{\mathrm{u}}$ and $\underline{\mathrm{O}-\mathrm{u}}$; b) PMb-Wn-An *a-u > PWn-An *a-u, whereas underwent 'split' > Mb a $, \underline{u}, \underline{o-u}$, and $\underline{a-i}$; c) PMb-Wn-An *s in ultima and penultima underwent 'split' > PWn$\mathrm{An}^{*} \underline{s}$ and $* \underline{\mathrm{h}}$, while 'retention' in $\mathrm{Mb}>\mathrm{Mb} \mathrm{s}$; d) PMb-Wn-An *g in ultima were 'substitution' > cluster nassal consonant $\mathrm{Mb} * \eta \mathrm{g}$, whereas 'retention' in PWn-An; and e) PMb-Wn-An *(m)b in penultima and ultima underwent 'split' > PWn-An * $\underline{\mathrm{b}}$ and $*$ (m)b and 'retention' in $\mathrm{Mb}>\mathrm{Mb}(\mathrm{m}) \mathrm{b}$. The diffferences prove that $\mathrm{Mb}$ and $\mathrm{PWn}-\mathrm{An}$ separated each other.

The phonological evidences which united $\mathrm{Mb}$ and PWn-An as two related languages are as follows: a) $\mathrm{PMb}-\mathrm{Wn}-\mathrm{An}$ *u in ultima position underwent 'retention' in $\mathrm{Mb}$ and $\mathrm{PWn}-\mathrm{An}$; b) PMb-Wn-An $*_{\mathrm{i}}$ in ultima position underwent 'retention', both in $\mathrm{Mb}$ as well as in PWn-An. This does not occur in other Sumba languages; and c) PMb-Wn-An *a in penultima underwent 'retention'> PWn-An *a-u and $\mathrm{Mb} \underline{\mathrm{a}}-$ $\underline{\mathrm{u}}$; and d) PMb-Wn-An *s and *h, both in ultima and penultima positions underwent 'split' > PWn-An * ${ }_{\underline{s}}$ and $* \underline{h}$ and $>\mathrm{Mb} \underline{\mathrm{s}}$ and $\underline{\mathrm{h}}$.

\section{REFERENCES}

Adelaar, K.A. (1991). Proto Malayic: the reconstruction of its phonology and parts of its lexicon and morphology. (Unpublished doctoral dissertation). Alblasserdam, Kanster B.V. 
Birnbaum, H. (1977). Linguistic reconstruction, its potential and limitation in new perspective. Washington DC: The Institute for the Study of Man.

Budasi, I. G. (2007). Kekerabatan bahasa-bahasa Sumba: Studi linguistic historis komparatif [title in English]. (Unpublished doctoral dissertation). Program Pascasarjana Universitas Gajah Mada, Yogyakarta.

Bynon, T. (1979). Historical linguistics. Cambridge: Cambridge University Press.

Crowley, T. (1992). An introduction to historical linguistics. Port Maresby: University of Papua New Guenia Press.

Durasid, D. (1990). Rekonstruksi protobahasa Barito. (Unpublished doctoral dissertation). Jakarta: Fakultas Pascasarjana Universitas Indonesia.

Dyen, I. (1978). Subgrouping and reconstruction. In Ali M \& M. Jazayery (Eds.), TICAL. PL Series D.68, 11-21.

Dyen, I. (1982). The present status of Austronesian subgrouping hypotheses. In D. Halim (Ed.), TICAL. PL Series C, 75, 31-35.

Fernandez, I. Y. (1988). Rekonstruksi proto bahasa Flores. (Unpublished doctoral dissertation). Program Pasca Sarjana Universitas Gadjah Mada, Yogyakarta.

Fernandez, I. Y. (2010). Subkelompok bahasa Jayapura dan implikasi kajiannya terhadap status subkelompok bahasa Austro-Melanesia serta Filum Papua dan Nugini. Paper presented at the Seminar Internasional Austronesia V Denpasar.

Grimes, B. F. (1988). Ethnologue: languages of the world. Dalas Texas: Summer Institute of linguistics, Inc.
Hock, H. H. (1988). Principles of historical linguistics. Berlin: Mouton de Gruyter.

Hockett, C. F. (1963). A course in modern linguistics. New York: The Machmillan.

Jeffers, R. J., \& Lehiste, I. (1979). Principles and methods for historical linguistics. Cambridge, Massachusetts: The MIT Press.

Keraf, G. (1991). Linguistik bandingan historis. Jakarta: Gramedia Pustaka.

Mandala, H. (2010). Evolusi fonologis bahasa Oirata dan kekerabatannya dengan bahasa-bahasa non austronesia di Timor Leste. (Unpublished doctoral dissertation). Program Pascasarjana Universitas Udayana, Denpasar

Mbete. A. M. (1990). Rekonstruksi proto bali-sasaksumbawa. (Unpublished doctoral dissertation). Fakultas Pascasarjana Universitas Indonesia, Jakarta.

Nothofer, B. (1975). The reconstruction of Proto Malayo-Javanic. VKI 73, Departement Pendidikan and Kebudayaan, 2008. Peta Bahasabahasa Nusantara. Jakarta: Pusat Bahasa.

Sneddon. (1978). Proto-Minahasan: Phonology and wordlist. Canberra: Dept. of Linguistics, Research School of Pacific Studies, Australian National University.

Swadesh, M. (1952). The origin and diversification of language. London: Rutledge and Kegan Paul.

Uhlenbeck, E. M. (1971). Indonesia and Malaysia. In T. Sebeok (Ed.) Current trend in linguistics, 8, 55-111. 